\title{
Morbid Obesity: A Review on the Reasons for Impediments to Physical Exercises and Social Activities
}

\author{
José Humberto Cardoso Resende1, Mattheus Duarte da Veiga Jardim², \\ Brena Thamyres de Andrade Irineu2, Leydeane Rosa Gomes Gontijo², Lucas Radi Cruvinel2, \\ Zeno Augusto de Sousa Neto ${ }^{2}$, Rodrigo Gonçalves de Oliveira², Daniel Soares de Araújo², \\ Emídio Silva Falcão Brasileiro 3
}

\author{
${ }^{1}$ UNIFAN, Work Coordinator, Aparecida de Goiânia, Brazil \\ ${ }^{2}$ UNIFAN, Academics of Medicine, Aparecida de Goiânia, Brazil \\ ${ }^{3}$ UNIFAN, Research Coordinator, Aparecida de Goiânia, Brazil \\ Email: jresen99@hotmail.com
}

How to cite this paper: Resende, J.H.C., Jardim, M.D.V., Irineu, B.T.A., Gontijo, L.R.G., Cruvinel, L.R., Sousa Neto, Z.A., Oliveira, R.G., Araújo, D.S. and Brasileiro, E.S.F. (2020) Morbid Obesity: A Review on the Reasons for Impediments to Physical Exercises and Social Activities. Modern Plastic Surgery, 10, 93-100.

https://doi.org/10.4236/mps.2020.103011

Received: May 15, 2020

Accepted: July 6, 2020

Published: July 9, 2020

Copyright $\odot 2020$ by author(s) and Scientific Research Publishing Inc. This work is licensed under the Creative Commons Attribution International License (CC BY 4.0).

http://creativecommons.org/licenses/by/4.0/

\begin{abstract}
Morbid obesity is regarded as a disease due to excess body weight, causing a silence of life as a whole and entailing the most varied disabilities for the person, such as: physical, social, psychological, affective, etc. It represents cases of "public health", thereby involving competent bodies in the development of solutions that encompass various medical specialties and other health fields, in addition to influencing the mind of these people, causing depression that, due to metabolic involvement, can evolve to the death of the individual. The participation of multidisciplinary health focuses on weight loss, freely and spontaneously, or on the indication of bariatric surgery. We know how difficult it is to lose weight. In order to achieve successful procedures, we recommend the "Obese Workshop" or pre- and post-surgical follow-ups close to the patients, with a view to avoiding recurrences or the "accordion effect" (very common), which can interfere with the Body Mass Index (BMI). Everyone, males and females, complained of tiredness and the impossibility of any physical exercise, even the lightest and simplest to be performed, in addition to the fact that they cannot attend gyms and are unable to open a simple door handle.
\end{abstract}

\section{Keywords}

Obesity, Hypertension, Diabetes, Bariatric, Illness, Physical Exercise 


\section{Introduction}

In this manuscript, we will focus only on morbid obesity, which, according to the Brazilian Society of Diabetes, grade III will take place when the BMI is higher than 40 [1], in the last 5 years, or 35 to those resistant for 2 years with chronic diseases [2].

Before the 1980s, we did not have the collaboration of bariatric surgery. Weight loss was conducted only with dietary restrictions, with which we almost never reached success. With the onset of Gastric Bypass, Gastric Band and duodenal surgeries [3], everything came to provide hope for people condemned by hypertension and diabetes, due to the capacity to improve metabolism [4] [5]. In 2019, the most widely used restrictive surgery was Gastric Bypass in a large proportion optional compared to other techniques.

We know that morbid obesity prevents patients from doing any type of physical exercises due to the difficulty in walking, deambulating and even getting out of bed [5] (Figure 1 and Figure 2). Differently from the obese, the morbid individuals do not lie that they eat a lot. They were followed-up for two years. The main complaint of all men was pendulous abdomen, while for women, it was gigantomasty (large and heavy breasts).

Everyone complained about the huge effort they had to make to perform minimal physical exercises, such as: opening doors or taking water from the filter. They are hypertensive and diabetic patients who, at the slightest effort, complain of breathing difficulties and tiredness. We draw the attention of the health authorities to their duty to adapt, in clinics and hospitals, the width of the doors and the safety of the toilets, which can be prepared in more reinforced ways, without the risk of breaking, which could cause greater complications for the physical state of the patients [6]. Among the risks inherent to the morbidly obese individuals, we have dozens of associated diseases, such as: diabetes, sleep apnea, high blood pressure, stroke, atrial fibrillation, heart diseases, asthma, hernias, gastric reflux, pancreatitis, infertility, varicose veins, besides the most striking: social stigmatization [7]. Patients report that they are not invited to events, they have difficulty in making a simple gesture and even the fact that they deal with restrictions when buying clothes [8]. Commonly, obesity leads to alcoholism, drugs and depression.

Pharmacological treatments would only work if accompanied by physical exercises, which we cannot achieve in cases of morbidity III [9]. During these more than 40 years caring for the obese patients and coordinating the "Workshop", I was able to evaluate the degree of difficulty encountered by the morbidly obese patients. I was once called to assist an obese man and asked where he was. They [staff] took me to the ambulance, opened the rear door, and then I perceived that the patient was lying there on the floor of the car. The patient weighed 205 $\mathrm{kg}$, so that he could only be weighed on a load weighing equipment, which was neither conventional nor decent.

Before a bariatric surgery, in several cases, we are called upon to perform the 
surgical healing of hernias and eviscerations, in order to allow the accomplishment of the restrictive surgery later (Figure 3 and Figure 4).

Usually, we firstly perform body relief surgery on giant breasts, where we remove more than $10 \mathrm{~kg}$ of body mass (Figure 5 and Figure 6), and then indicate bariatric surgery, with the purpose of reducing intraoperative surgical risks.

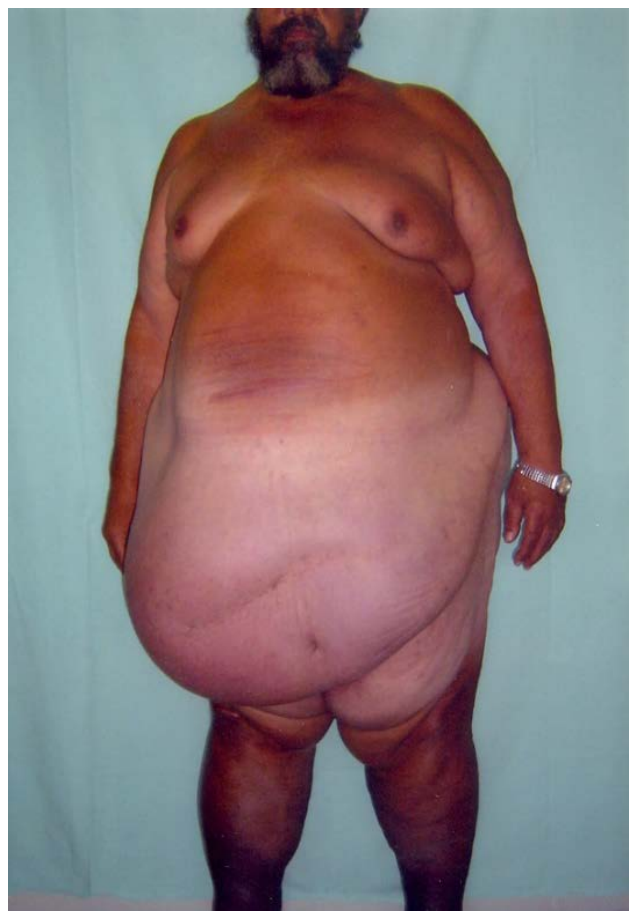

Figure 1. Morbid obese male patient with giant abdomen.

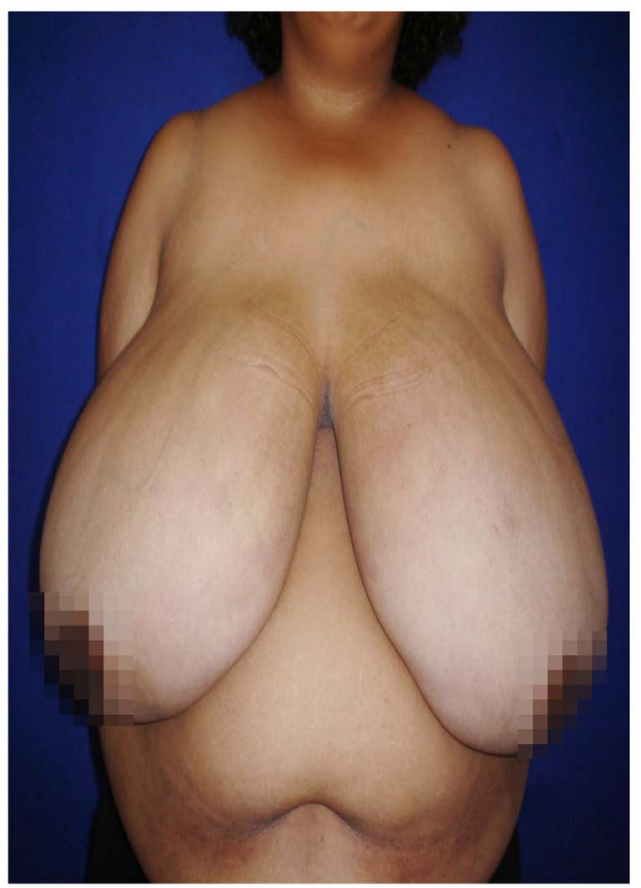

Figure 2. Morbid obese female patient with gigantomasty. 


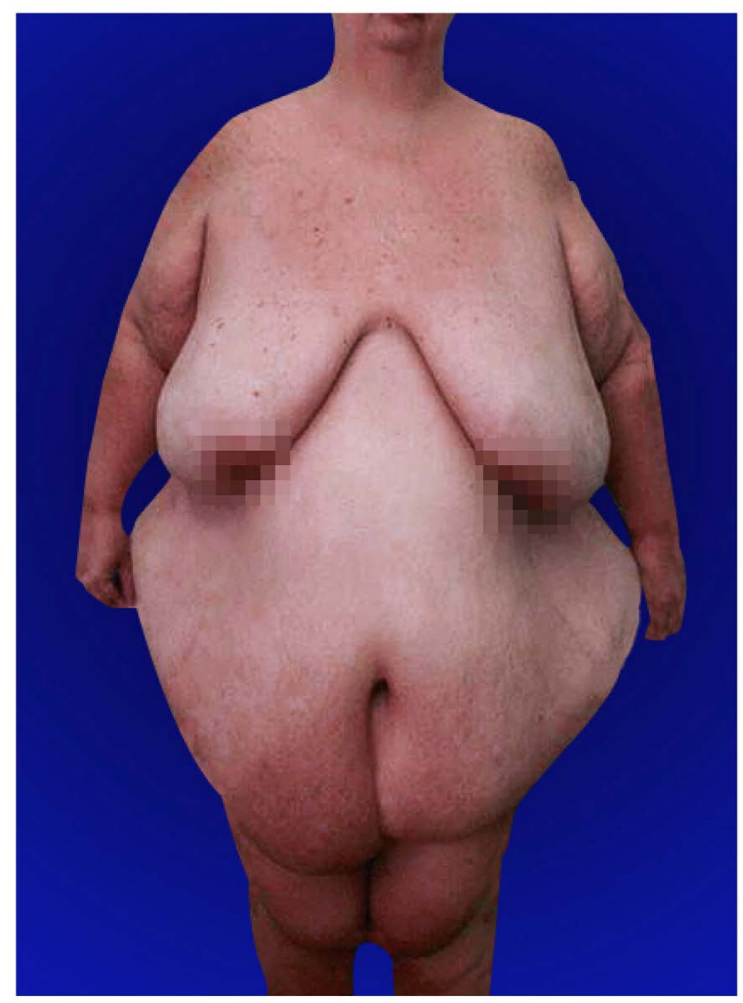

Figure 3. Obese male patient with hernia and evisceration.

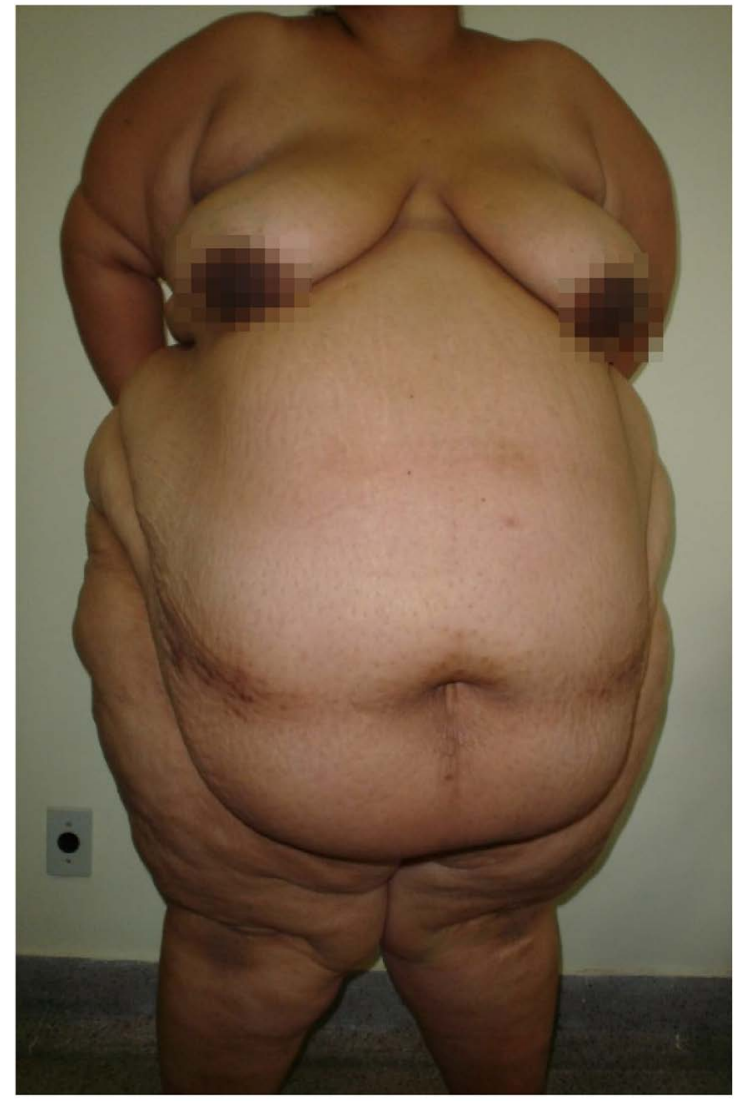

Figure 4. Obese female patient with hernia and diastase in straight abdominal muscles. 


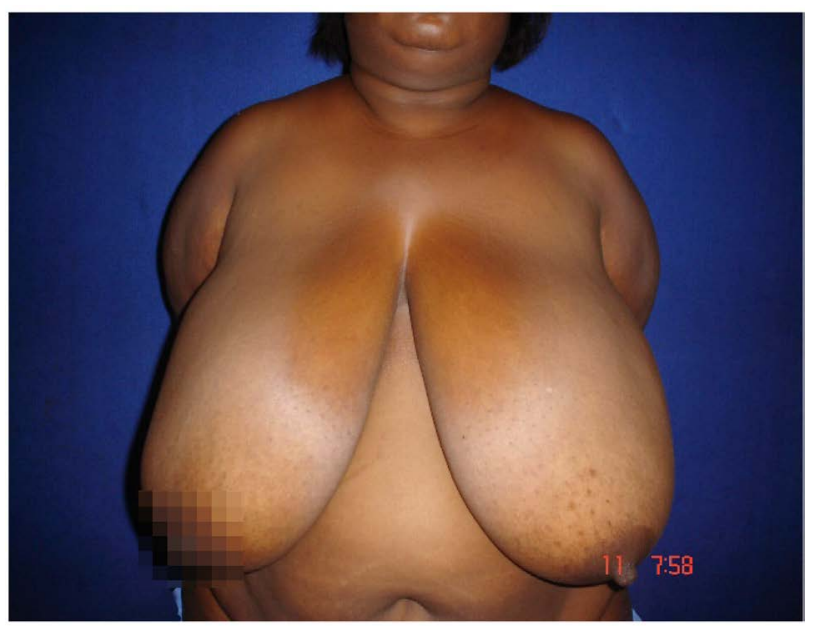

Figure 5. Preoperative of gigantomasty.

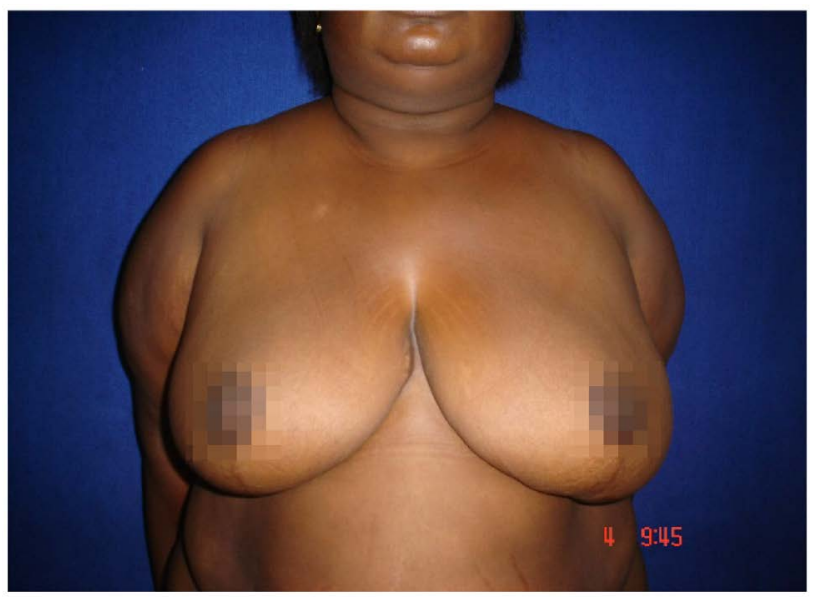

Figure 6. Postoperative with 5 days.

In many cases, the morbidly obese men have a thin voice and have their genitals covered up. Breasts are not always considered to be organs of identification when it comes to morbidly obese people. In Figure 6, we can note that there was total graft of the areola-papillary complex and decreased weight of the breasts, thereby greatly improving the quality of life of patients, even before the bariatric surgery is done.

All patients who lose more than $50 \mathrm{~kg}$, during the postoperative period, request plastic surgery to have again the same type of body that they had before obesity, as if, by miracle, this could happen. We remember that, in any case, weight loss brings great satisfaction to most patients because they have reached a better quality of life, as well as the power to reintegrate into society in terms of clothing [10]. In this manuscript, we are not addressing morbid obesity in adolescence or childhood, where emotional and psychological problems (bullying) are sometimes even greater [11]. Ethics and respect have always been priorities in our studies, without any identification of the patients and with all Informed Consent Forms duly signed. 


\section{Material}

We selected 10 patients, 4 men and 6 women, where we noticed the difficulty in identifying them in the first observation, as they are similar except for the beard and the amount of body hair (Figure 1). In men, we identified more hernias and eviscerations in the abdominal part (Figure 3) than in women. In contrast, in women, we identified breast gigantism in $80 \%$ of them (Figure 2) or breast ptosis without conditions for conventional mammoplasty, when we use the Resende Technique [12] [13] to remove the excess skin, with subsequent areola grafting. Firstly, we recommend surgery for giant breasts [14], before bariatric surgery, or, in cases of abdominal gigantism (Figure 4), excision of the abdominal fat apron. We recommend special beds, adapted bathrooms and a lot of attention in the postoperative period. In all cases, body relief surgeries are highly complex and multidisciplinary teams should be convoked, including nutrition professionals [14].

We recommended weight loss of at least $5 \mathrm{~kg}$ before restrictive surgery. This is because it was noticed that, after losing $5 \mathrm{~kg}$ of body mass, there was a significant improvement in hypertension and a decrease in blood glucose levels. During the anamnesis, we heard the main complaints of the 10 patients:

- "I feel very tired".

- "I can't even get up".

- "I can't find suitable clothes to buy".

- "I have impediments to having sexual intercourses".

- "I can't get in cars".

- "I'm ashamed of myself".

- "I find difficulties in showering".

- "I always feel hungry".

- "Nobody wants to date me".

- "He separated from me because I'm chubby".

- "I’m rejected by society".

\section{Discussion}

The visual absurdity is so intriguing and complex that it will depend on the degree of experience of each medical team, involving anesthesia and the type of surgery that must be performed first. It will depend on the degree and shape of each body, in order to define whether plastic surgery first enters to perform body relief or whether bariatric surgery is performed before. We always choose the technique that is most suitable for each case of morbid obesity. Unfortunately, many patients progress to death before they can achieve their dreams. The team needs to be prepared to decide what is best for the patient.

We know that these cases concern public health and we still do not have an exclusive hospital for obese people in our country. This would be necessary because $40 \%$ of the Brazilian population is overweight, besides the fact that we have a high rate of deaths from hypertension and diabetes. Accordingly, a new 
field is introduced in the surgical specialties for this discussion. We highlight the importance of the care that every morbidly obese person requires, as well as the dangers, including legal ones, that can arise. We also draw attention to the fact of how a successful surgical procedure can lead to considerable improvements in the quality of life of patients with this illness.

\section{Conclusions}

In all patients, males and females, we observed a considerable improvement in the metabolic status and in the appearance of body vanity. It is as if we gave back to each individual the will to live and the hope of being reintegrated into society. A male patient made the following observation: "When I was fat, I was ugly, with these skin folds, I am horrible, but only until I reach all the plastic surgeries I need!" With the involvement in studies on obesity, we can state that the patients who attended the "Obese Workshop" performed better than those who arrived at the surgery without emotional preparation and without knowing all the phases that involve the metabolic and plastic surgeries in question.

We conclude that, firstly, we should be focused on saving lives, and then try to reintroduce them into society. Moreover, we should manage to achieve a plastic surgery team prepared and trained to continue making corrections of the excess skin left by weight loss.

\section{Conflicts of Interest}

The authors declare no conflicts of interest regarding the publication of this paper.

\section{References}

[1] Milech, A., Oliveira, J. and Vencio, S. (2015-2016) Brazilian Diabetes Society Guidelines.

https://www.google.com.br/url?sa=t\&rct=j\&q=\&esrc=s\&source=web\&cd=1\&ved=2ah UKEwjWxLWm2tnoAhW2GrkGHcnuAxMQFjAAegQIAhAB\&url=https\%3A\%2F\% 2Fwww.diabetes.org.br\%2Fprofissionais\%2Fimages\%2Fdocs\%2FDIRETRIZES-SBD-2 015-2016.pdf\&usg=AOvVaw35_kNhv9afootr01FW2UjS

[2] Federal Council of Medicine (2020) FCM Details List of Comorbidities That May Lead to Indication for Bariatric Surgery.

https://portal.cfm.org.br/index.php?option=com_content\&view=article\&id=25939

[3] Tonatto-Filho, A.J., et al. (2019) Bariatric Surgery in the Brazilian Public Health System: The Good, the Bad and the Ugly, or a Long Way to Go. Yellow Sign! ABCD, Arquivos Brasileiros de Cirurgia Digestiva, 32, e1470. https://doi.org/10.1590/0102-672020190001e1470

[4] Brazil. Ministry of Health (2020) Homepage DATASUS. Hospital Information Systems-SUS (SIH/SUS).

http://tabnet.datasus.gov.br/cgi/deftohtm.exe?sih/cnv/qiuf.def

[5] Streb, A.R. and Del Duca, G.F. (2020) Obesity and Physical Exercise: Latent Challenges. Biomotriz, 13, 1-5.

http://revistaeletronica.unicruz.edu.br/index.php/BIOMOTRIZ/article/viewFile/819 $\underline{0 / p d f \_147}$ 
[6] Dias, C. and Verona, A. (2019) Overweight, Obesity and Education in Brazil. Health Magazine (Sta. Maria), Brazil, 45.

[7] De Melo, M.E. (2020) Diseases Triggered or Aggravated by Obesity. Brazilian Association for the Study of Obesity and Metabolic Syndrome-BASOMS. https://abeso.org.br/wp-content/uploads/2019/12/5521afaf13cb9.pdf

[8] Marcon, E.R., Gus, I. and Neumann, C.R. (2011) Impact of a Minimum Supervised Exercise Program on Cardiometabolic Risk in Patients with Morbid Obesity. Arquivos Brasileiros de Endocrinologia e Metabologia, São Paulo, 55, 331-338 http://www.scielo.br/scielo.php?script=sci_arttext\&pid=S0004-27302011000500006

[9] Moraes, J. da M., Caregnato, R.C.A. and Schneider, D. da S. (2014) Quality of Life before and after Bariatric Surgery. Acta Paulista de Enfermagem, São Paulo, 27, 157-164.

http://www.scielo.br/scielo.php?script=sci_arttext\&pid=S0103-21002014000200012 \&lng=pt\&nrm $=$ iso

[10] Luz, D.M.D. and Encarnação, J.N. (2008) Advantages and Disadvantages of Bariatric Surgery for the Treatment of Morbid Obesity. Brazilian Journal of Obesity, $\mathrm{Nu}$ trition and Weight Loss, São Paulo, 2, 376-383.

https://www.google.com/url?sa=t\&rct=j\&q=\&esrc=s\&source=web\&cd=4\&ved=2ah UKEwjv8Jvc5dnoAhUQE7kGHeXhAfcQFjADegQIAhAB\&url=http\%3A\%2F\%2Fw ww.rbone.com.br\%2Findex.php\%2Frbone\%2Farticle\%2Fview\%2F99\%2F97\&usg=A OvVaw2AmpoxAiCFYbSeYUSMJ9Iv

[11] Sousa, P.M.L. (2006) Adolescent Obesity: Psychological Aspects and school Performance. Dissertation (Master)-Pedagogical Psychology Course, Faculty of Psychology and Educational Sciences, University of Coimbra, Coimbra, Portugal. http://hdl.handle.net/10400.8/218 Acessed on April 08

[12] Resende, J.H.C. (2003) Gigantomasty. In: Plastic Surgery-Fundamentals and Art-Aesthetic Surgery. MEDSI, São Paulo, vol. 1, 555-561.

[13] Resende, J.H.C. (2008) Resende's Technique for Correcting Gigantomasty-Body Relief Surgery, Treated Plastic Surgery in Obesity. Ed. Rubio, Rio de Janeiro, 357-365.

[14] Resende, J.H.C., de Moura, Á.I., Mariano, A.C.A., Silva, H.K., Silva, H.L., Campos, I.A., de Lima, L.C.F., Gabriel, M.B. and Silverio, W.O. (2019) Gigantomasty in Female Workers: "Public Health Cases". Modern Plastic Surgery, 9, 1-7. https://doi.org/10.4236/mps.2019.91001 